\title{
INFLUÊNCIA DO PROCESSAMENTO POR VIA ÚMIDA E TIPOS DE SECAGEM SOBRE A COMPOSIÇÃO, FÍSICO QUÍMICA E QUÍMICA DO CAFÉ (CoffeaarabicaL).
}

\author{
Influence of the wet processing and drying types on chemical and \\ physicochemical composition of coffee (Coffea arabica L.)
}

\author{
Mariá Auxiliadora Santos ${ }^{1}$, Sára Maria Chalfoun ${ }^{2}$, Carlos José Pimenta $^{3}$
}

\begin{abstract}
RESUMO
O café (Coffea arabica L.) é um importante produto de exportação brasileira, por fazer parte do hábito alimentar da população de diversos países. Sua produção vem passando por transformações tecnológicas que têm como objetivo agregar valores qualitativos ao produto destinado tanto para mercado interno como externo. A exportação do café e de produtos alimentícios deve se adequar aos programas de qualidade estabelecidos por acordos políticos internacionais. Assim sendo, objetivou-se, nesse estudo, verificar a influência do método de preparo via úmida com tipos distintos de secagens, na obtenção do café cereja descascado, sobre a composição, físico-química e química do café. Houve influência da forma, preparo e tipo de secagem sobre as principais características estudadas. $\mathrm{O}$ café cereja descascado apresentou diferenças nos principais indicadores químicos físico-químicos e com uma superioridade para esse método de preparo com secagem exclusiva no terreiro, em diversos aspectos. Houve redução na condutividade elétrica, lixiviação de potássio e aumento da atividade da polifenoloxidase.
\end{abstract}

Termos para indexação: Cereja descascado, polifenoloxidase, terreiro.

\section{ABSTRACT}

Coffee (Coffea arabica L.) is an important Brazilian export product, being part of the eating habit in several countries. Its production has experienced technological transformations, with the aim at adding quality values to the product destined to internal as well as to external market. The export of coffee and food products must adjust to the quality programs established by international political agreements. In this context, this work was carried out to verify the influence of the wet processing using different drying types on the obtentainment of the husked coffee cherry on the chemical and physicochemical composition of the coffee. There was influence of the preparation and the drying type methods on the main studied characteristics. The peeled red cherry coffee presented differences in the main chemical and physicochemical indicators, with a superiority in the preparation method with exclusive drying on the patio, in several aspects. Reduction in the electric conductivity and potassium leaching was observed as well as increase in the polyphenoloxidase activity.

Index terms: Peeled red cherry, polyphenoloxidase, coffee drying patio

(Recebido em 20 de outubro de 2005 e aprovado em 3 de janeiro de 2008)

\section{INTRODUÇÃO}

A indústria cafeeira, atualmente, apresenta crescente segmentação quanto às características de qualidade do café que são relacionadas à sua origem e formas de preparo, que dependem dos fatores intrínsecos e extrínsecos; a interação entre esses fatores garantem a expressão final das características de sabor e aroma da bebida (PIMENTA, 2001)

O preparo do café inicia-se com o processo de lavagem que é importante prática por reduzir, ou eliminar determinados defeitos como separação da fração bóia (GUIMARÃES, 1995; ORNELLAS, 2001), proporcionando secagem de lotes mais homogêneos. O preparo para a secagem pode ser feito por via seca com a produção de cafés naturais; a fração bóia tem seu preparo exclusivo pela via seca, ou por via úmida, técnica adotada por diversos países da América Central originando cafés despolpados, com a presença da fase fermentativa. É uma tecnologia que agrega valor ao café e contribui para alcançar boas cotações no mercado internacional e proporcionar uma bebida suave (BRANDO, 1999; SIQUEIRA, 2003). Entretanto essa técnica requer investimentos mais elevados e utilização mais intensiva da mão-de-obra e maiores gastos de água em relação ao preparo natural (STEGEN, 2003).

\footnotetext{
'Nutricionista, Mestre em Ciência dos Alimentos - Departamento de Ciência dos Alimentos/DCA - Universidade Federal de Lavras/UFLA - Cx. P. 3037 37200-000 - Lavras, MG - marsolterra2004@yahoo.com.br

${ }^{2}$ Fitotecnista, Doutora, Pesquisadora - Centro Tecnológico do Sul Minas - Empresa de Pesquisa Agropecuária de Minas Gerais/EPAMIG - Cx. P. 176 37200-000 - Lavras, MG - chalfoun@ufla.br

${ }^{3}$ Doutor em Ciência dos Alimentos, Professor - Departamento de Ciência dos Alimentos/DCA - Universidade Federal de Lavras/UFLA - Cx. P. 3037 37200-000 - Lavras, MG - carlos.pimenta@pq.cnpq.br
} 
Recentemente no Brasil, a técnica por via úmida, foi inovada com a exclusão da fase de fermentação (AFONSO JÚNIOR et al., 2001), surgindo a produção de cafés cereja desmucilados e descascados mecanicamente. $\mathrm{Na}$ obtenção do cereja descascado, a casca e polpa do fruto são removidas de forma mecânica, e a mucilagem é secada juntamente com o pergaminho, num processo conhecido como intermediário entre o natural e o despolpado ou desmucilado, que apesar de ter características próprias, tende comumente para as características do café natural, uma vez que os produtos da mucilagem são transferidos para o grão (BRANDO, 1999; PEREIRA 1997).

A técnica via úmida, sem a fase de fermentação, atua como medida preventiva, agilizando o processo de secagem com a retirada da casca; ou como ação corretiva para reduzir falhas existentes na colheita ou de infraestrutura (volume da produção e agregar valor às características sensoriais desejáveis), uma vez que a secagem de café é considerada um dos entraves da qualidade no mercado atual (AFONSO JÚNIOR et al., 2001; BORÉM, 2004). De acordo com o IBC (1977), a faixa ideal de secagem fica em torno de $11 \%$ e $13 \%$ de umidade. Entre as formas de secagem, muitos cafeicultores fazem uso da forma convencional, sendo o terreiro um processo lento e com risco de danos mecânicos pelas condições adversas ao grão e pela presença microbiana (GIRANDA, 1998; PIMENTA, 2001). Entretanto pode-se obter cafés de boa qualidade, quando a construção dos terreiros e as formas de manejo são aplicadas corretamente (BATISTA, 2005; BORÉM 2004). A prática da secagem mista vem apresentando diversas vantagens, reduzindo a umidade inicial e o volume de café no secador (GIRANDA, 1998). Economicamente, é indicado que o café tenha uma présecagem no terreiro até atingir $30 \%$ de umidade na base seca, visando aspecto econômico no produto final.

O Brasil vem se inserindo no mercado nacional e, ou, internacional em termos de qualidade tecnológica (LEITE, 1998; SILVA et al., 2004). A superioridade da via úmida, com exclusão da fase fermentativa, tem demonstrado superioridade em relação aos cafés naturais Villela (2002).

Os processos técnicos, juntamente com a adoção de métodos químicos e físico-químicos, garantem a qualidade do café (CARVALHO et al., 1994). A lixiviação de potássio e a condutividade elétrica são parâmetros que têm sido utilizados como indicadores consistentes da integridade de membranas celulares (MCDONALD, 1993; PIMENTA, 2001).

Assim sendo a proposta deste trabalho foi verificar a influência do preparo do café, pela tecnologia via úmida na produção de desmucilado e descascados mecanicamente, submetidos a secagem no terreiro e mista, sobre a composição físico-química do café.

\section{MATERIALE MÉTODOS}

O preparo das amostras referentes aos frutos de café (Coffea arabica L.), da cultivar Mundo Novo, foi realizado na fazenda Santa Rita no Município de Piumhi- MG, altitude 750 metros, no ano agrícola 2002/2003. Depois de colhido, o café foi conduzido ao processo de lavagem e preparo descascado e desmucilado mecanicamente inicio da secagem.

As amostras foram secadas em terreiros distintos de alvenaria, cujo tempo de secagem no terreiro foram 20,7 e 8 dias, respectivamente para a fração de café bóia, descascado e desmucilado. Parte das amostras foram submetidas ao processo de secagem mista, quando o café atingiu meia seca (30\% de umidade) no terreiro. O tempo para secagem mista foi distinto entre os tipos de café: a fração bóia 05 dias no terreiro e 45 horas no secador do tipo vertical; o café descascado 03 dias no terreiro e 45 horas no secador do tipo horizontal e o desmucilado com 02 dias no terreiro e 45 horas, no secador, tipo horizontal. As temperaturas utilizadas foram $30^{\circ} \mathrm{C}$ na massa e $75^{\circ} \mathrm{C}$ na saída da fornalha.

Após a secagem os cafés foram encaminhados para o Laboratório Dr Alcides de Carvalho da EPAMIG, no município de Lavras- MG para posterior análises físicas, físico-químicas e químicas no grão cru.

Delineamento experimental: Inteiramente casualisado com quatro repetições.

Análise Estatística: O resultado obtido foi submetido à análise de variância para comparação entre médias utilizando-se os testes de Scott-Knott e teste T (LSD), a 5\% de probabilidade.

Lixiviação de potássio: A determinação da quantidade de potássio lixiviado foi realizada em fotômetro de chama DIGIMEDdm-61, após cinco horas de embebição dos grãos (PRETE, 1992). Os resultados obtidos foram calculados e a lixiviação de potássio expressa em ppm.

Condutividade elétrica: A condutividade elétrica foi determinada segundo Loeffler et al. (1988). Determinada através de adaptação da metodologia proposta por Prete (1992), utilizando-se subamostras de 50 grãos de cada amostra original.

Atividade da Polifenoloxidase: $\mathrm{O}$ extrato enzimático utilizado na determinação da atividade da polifenoloxidase foi por meio de adaptação do processo de extração descrito por Draeta \& Lima (1976), e determinada pelo método descrito por Ponting \& Joslyng (1948), utilizando-se extrato de amostra sem DOPA em branco. 
Sólidos solúveis totais: Para a determinação de SST, os grãos foram triturados, acrescidos de água e filtrados. Os resultados foram expressos em ${ }^{\circ}$ Brix, conforme normas da AOAC (1990).

Açúcares totais e redutores: Os açúcares totais e redutores foram extraídos pelo método de Lane-Enyon, citados pela AOAC (1990) e determinados pela técnica de Somogy, adaptada por Nelson (1944), sendo os resultados expressos em \%MS.

$\mathrm{pH}: \mathrm{O} \mathrm{pH}$ foi determinado a partir do mesmo extrato utilizado na determinação da acidez titulável total, foi medido utilizando-se o peagâmetro Digital -PG -1000, os resultados foram expressos em \%MS.

\section{RESULTADOS E DISCUSSÃO}

\section{Condutividade elétrica e lixiviação de potássio}

De acordo com a Tabela 1 , houve diferenças significativas de condutividade elétrica entre os tipos de preparo do café e entre as formas de secagem. O café descascado seco no terreiro apresentou menor valor de condutividade elétrica em relação aos demais tipos e à sua secagem mista. O café fração bóia apresentou maior condutividade elétrica com sua secagem no terreiro seguido do desmucilado, ambos quando submetidos à secagem no secador apresentaram uma menor condutividade elétrica, conforme McDonald (1993), cafés de melhor qualidade apresentam menores valores de condutividade elétrica.

O valor elevado de condutividade elétrica observada na fração bóia pode ser justificado por esse tipo de café apresentar comprometimento da qualidade, uma vez que há perda da integridade da membrana préexistente tornando esses grãos suscetíveis à maior condutividade elétrica; essa característica da fração bóia, associada à forma de secagem no terreiro condicionou esse resultado. A condutividade elétrica e lixiviação de potássio avaliam a integridade das membranas celulares de grãos e frutos constituindo-se importantes parâmetros na avaliação da qualidade de cafés (PIMENTA, 2001; PRETE, 1992; SILVA et al., 2004).

O café desmucilado apresentou maior valor de condutividade elétrica com a secagem no terreiro e esse fato pode estar associado à ocorrência de danos mecânicos, durante o processo de desmucilagem, uma vez que essa substância encontra-se aderida ao pergaminho. Segundo Zapp et al. (1990), os danos intensos e as rupturas de baixa intensidade são difíceis de serem detectados tornando os frutos e os grãos susceptíveis a novos defeitos.

\section{Atividade enzimática polifenoloxidase}

A Tabela 2 indica que houve diferença significativa quanto ao tipo de secagem entre os tipos de preparo do café, para atividade da polifenoloxidase. Avaliando os resultados observa-se que o café bóia e desmucilado, secos em terreiro, não diferiram entre si apresentando menores valores de atividade enzimática em relação ao descascado. A seqüência da evolução dos dados com referência aos parâmetros analisados: lixiviação de potásssio, condutividade elétrica e compostos fenólicos apresentam resultados com tendência ao processo degenerativo da membrana celular e baixa atividade enzimática da polifenoloxidase.

O café descascado apresentou maior atividade enzimática no terreiro, reduzindo essa atividade quando submetido à secagem no secador. Tal resultado sugere que a causa da perda da integridade da membrana celular dos grãos, seja por presença de microrganismos originados de contaminação cruzada presente na estrutura do equipamento ou durante o processo de secagem no terreiro, com infestação de fungos de forma superficial pela presença

Tabela 1 - Valores médios de condutividade elétrica, lixiviação de potássio, em dois tipos de pré-preparo (bóia, descascado e desmucilado) e submetido a dois tipos de secagem (terreiro e mista).

\begin{tabular}{|c|c|c|c|c|}
\hline \multirow[t]{3}{*}{ Tipos de Café } & \multicolumn{2}{|c|}{$\begin{array}{l}\text { Condutividade Elétrica } \\
\mu \mathrm{Scm}^{-1} / \mathrm{g} \text { da amostra }\end{array}$} & \multicolumn{2}{|c|}{$\begin{array}{c}\text { Lixiviação de Potássio } \\
\text { (ppm/g da amostra) }\end{array}$} \\
\hline & \multicolumn{2}{|c|}{ Secagem* } & \multicolumn{2}{|c|}{ Secagem* } \\
\hline & Terreiro & Terreiro/Mista & Terreiro & Terreiro/Mista \\
\hline Bóia** & $200,82 \mathrm{aA}$ & $124,48 \mathrm{bA}$ & $50,89 \mathrm{aA}$ & $22,04 \mathrm{bB}$ \\
\hline Descascado $^{* *}$ & $121,56 \mathrm{bC}$ & $145,07 \mathrm{aA}$ & $33,43 \mathrm{aC}$ & $27,73 \mathrm{bA}$ \\
\hline \multirow[t]{2}{*}{ Desmucilado** } & $146,39 \mathrm{aB}$ & $88,49 \mathrm{aB}$ & $44,79 \mathrm{aB}$ & $20,277 \mathrm{bB}$ \\
\hline & \multicolumn{2}{|c|}{$\mathrm{CV} \%=9,38$} & \multicolumn{2}{|c|}{$\mathrm{CV} \%=8,63$} \\
\hline
\end{tabular}

\footnotetext{
* Médias seguidas de letras maiúsculas distintas nas linhas diferem entre si pelo teste de T (LSD), a 5\% de probabilidade

** Médias seguidas de letras minúsculas distintas nas colunas diferem entre si pelo teste de Scott-Knott, a 5\% de probabilidade
} 
da mucilagem. Quando esse café descascado foi transferido para o secador, esse processo provocou alterações dos compostos químicos e redução da polifenoloxidase. Esse resultado corrobora com Amorim \& Amorim (1977), uma vez que a pré-secagem no terreiro pode ocasionar um possível processo fermentativo.

Tabela 2 - Valores médios e erro padrão de polifenoloxidase (nmol/g.min), em três tipos de café (bóia, descascado e desmucilado) e submetido a dois tipos de secagem (terreiro e mista).

\begin{tabular}{|c|c|c|}
\hline \multirow{3}{*}{ Tipos de Café } & \multicolumn{2}{|c|}{ Polifenoloxidase ( nmol/g.min) } \\
\hline & \multicolumn{2}{|c|}{ Secagem* } \\
\hline & Terreiro & Terreiro/Secador \\
\hline Bóia** & $61,53 \mathrm{bB}$ & $64,27 \mathrm{aA}$ \\
\hline Descascado $* *$ & $63,98 \mathrm{aA}$ & $61,82 \mathrm{bB}$ \\
\hline Desmucilado $* *$ & $61,78 \mathrm{bB}$ & $64,31 \mathrm{aA}$ \\
\hline
\end{tabular}

*Médias seguidas de letras maiúsculas distintas nas linhas diferem entre si pelo teste de T (LSD), a 5\% de probabilidade

** Médias seguidas de letras minúsculas distintas nas colunas diferem entre si pelo teste de Scott - Knott, a 5\% de probabilidade

\section{Açúcares totais e sólidos solúveis totais}

Com relação aos teores de açúcares totais a Tabela 3 indica que não houve diferenças significativas entre os tipos de pré-preparo com secagem no terreiro. O tipo de pré-preparo para o café cereja descascado, secagem mista, apresentou diferença significativa e inferior em relação aos demais cafés. A diminuição dos açúcares totais com a secagem mista pode ser atribuída à possível ocorrência de processo fermentativos por microrganismos, por ser um potente substrato. Os teores de açúcares totais encontrados no presente trabalho estão acima dos teores verificado por Leite (1998), segundo o autor as condições climáticas e a região contribuem para as alterações sobre o desdobramento de amido a açúcares, levando os cafés dessa região a maiores teores de açúcares; e acima dos valores apresentados pela OIC (1992), apesar da fração bóia, secagem mista, ter apresentado maiores valores de sólidos solúveis totais e valores superiores a 30,72\%, encontrado por Villela (2002).

\section{Açúcares Redutores e não redutores}

A avaliação dos teores médios dos açucares não redutores, expressos na Tabela 4 indica que houve diferença significativa quanto ao processamento do cereja descascado entre os demais cafés, com secagem no secador. O tipo de preparo por via úmida, para o café cereja descascado mecanicamente, seco em terreiro, apresentou diferença significativa para o açúcar não redutor. Esses resultados concordam com os dados em literatura, os açúcares no café são responsáveis pelo sabor e aroma característicos da bebida (BRANDO, 1999). Villela (2002) recomenda uma pré-secagem ao sol no intuito de preservar parte das substâncias consideradas importantes para a qualidade da bebida. Quanto à secagem no terreiro, o resultado obtido apresentou teores semelhantes aos dados observados por Malta et al. (2003), exceto o desmucilado que apresentou valor inferior a 7,22\%.

\section{pH observado em diferentes tipos de preparo e secagem}

A tabela 5 apresenta a diferença significativa entre os valores de $\mathrm{pH}$, quanto à forma de secagem. Sendo que os cafés secos em terreiro apresentaram maior valor de $\mathrm{pH}$, tal fato pode ser atribuído à secagem mista ter contribuído para a ocorrência de fermentações, elevando o teor de acidez desses cafés.

Os tipos de café bóia, descascado e desmucilado não apresentaram diferenças significativas quanto ao $\mathrm{pH}$. Tais resultados concordam com aqueles obtidos por Siqueira (2003), que não observou diferenças quanto ao $\mathrm{pH}$ para despolpados e descascados.

Tabela 3 - Valores médios de açúcares totais, sólidos solúveis totais em café processados via seca e via úmida (bóia, descascado e desmucilado) e submetido a dois tipos de secagem (terreiro) terreiro e secador).

\begin{tabular}{|c|c|c|c|c|}
\hline \multirow{3}{*}{ Tipos de Café } & \multicolumn{2}{|c|}{ Açúcares Totais } & \multicolumn{2}{|c|}{ Sólidos Solúveis Totais } \\
\hline & \multicolumn{2}{|c|}{ Secagem $\% *$} & \multicolumn{2}{|c|}{ Secagem\%* } \\
\hline & Terreiro & Mista & Terreiro & Mista \\
\hline Bóia** & $6,97 \mathrm{aA}$ & $7,21 \mathrm{aA}$ & $34,37 \mathrm{aA}$ & $32,81 \mathrm{aA}$ \\
\hline Descascado** & $7,50 \mathrm{aA}$ & $5,71 \mathrm{bB}$ & $20,31 \mathrm{bB}$ & $29,680 \mathrm{aA}$ \\
\hline \multirow[t]{2}{*}{ Desmucilado** } & $6,34 \mathrm{aA}$ & $6,58 \mathrm{aA}$ & $26,56 \mathrm{aA}$ & $20,83 \mathrm{bB}$ \\
\hline & \multicolumn{2}{|c|}{$\mathrm{CV} \%=7,72$} & \multicolumn{2}{|c|}{$\mathrm{CV} \%=11,81$} \\
\hline
\end{tabular}

*Médias seguidas de letras maiúsculas distintas nas linhas diferem entre si pelo teste de T (LSD), a 5\% de probabilidade.

** Médias seguidas de letras minúsculas distintas nas colunas diferem entre si pelo teste de Scott-Knott, a 5\% de probabilidade 
Tabela 4 - Valores médios e erro padrão de açúcares redutores, açúcares não redutores em três tipos de café (bóia, descascado e desmucilado) e submetido a dois tipos de secagem (terreiro; terreiro e secador).

\begin{tabular}{|c|c|c|c|c|}
\hline \multirow{3}{*}{ Tipos de Café } & \multicolumn{2}{|c|}{ Açúcares não Redutores } & \multicolumn{2}{|c|}{ Açúcares Redutores } \\
\hline & \multicolumn{2}{|c|}{ Secagem\%* } & \multicolumn{2}{|c|}{ Secagem\%* } \\
\hline & Terreiro & Mista & Terreiro & Mista \\
\hline Bóia** & $6,24 \mathrm{aA}$ & $6,36 \mathrm{aA}$ & $0,39 \mathrm{bA}$ & $0,52 \mathrm{aA}$ \\
\hline Descascado** & $6,67 \mathrm{aA}$ & $5,27 \mathrm{bB}$ & $0,46 \mathrm{aA}$ & $0,15 \mathrm{bB}$ \\
\hline \multirow[t]{2}{*}{ Desmucilado $^{* *}$} & $5,84 \mathrm{aA}$ & $6,01 \mathrm{aA}$ & $0,18 \mathrm{aB}$ & $0,25 \mathrm{aA}$ \\
\hline & \multicolumn{2}{|c|}{$\mathrm{CV} \%=7,7$} & \multicolumn{2}{|c|}{$\mathrm{CV} \%=20,1$} \\
\hline
\end{tabular}

*Médias seguidas de letras maiúsculas distintas nas linhas diferem entre si pelo teste de T (LSD), a 5\% de probabilidade.

** Médias seguidas de letras minúsculas distintas nas linhas diferem entre si pelo teste de Scott-Knott, a 5\% de probabilidade.

Tabela 5 - Valores médios de $\mathrm{pH}$, em café submetido a dois tipos de secagem (terreiro e mista).

\begin{tabular}{crr}
\hline Tipos de secagem & Terreiro & Mista \\
\hline $\mathrm{pH}$ & $5,83 \mathrm{~A}$ & $5,59 \mathrm{~B}$ \\
\hline & $\mathrm{CV} \%=1,35$
\end{tabular}

*Médias seguidas de letras maiúsculas distintas nas linhas diferem entre si pelo teste de T (LSD), a 5\% de probabilidade

\section{CONCLUSÕES}

De maneira geral, o café obtido pelo método de via úmida na obtenção do café cereja descascado apresentou maior número de indicadores positivos quanto à qualidade. O café bóia e desmucilado, apresentaram indicadores de qualidade inferiores em relação ao café descascado seco no terreiro sendo que a secagem mista foi benéfica a esses cafés. O café cereja descascado seco em terreiro reduziu a condutividade elétrica e a lixiviação de potássio aumentou açucares totais e atividade da polifenoloxidase.

\section{REFERÊNCIAS BIBLIOGRÁFICAS}

AFONSO JÚNIOR, P. C.; CORRÉA, P. C.; OLIVEIRA, T. T. de; OLIVEIRA, M. G. de A. Avaliação da qualidade de grãos de café preparados por "via seca" e "via úmida" em função da condição e período de armazenamento. Revista de Armazenamento, Viçosa, v. 23, n. 3, p. 46-53, 2001. Edição especial.

AMORIM, H. V.; AMORIM, V. L. Coffee enzyme and coffee quality. In: ORY, R. L.; SAINT ANGELO, A. J. (Eds.). Enzymes in food and beverage processing. Washington, DC: American Chemical Society, 1977. p. 27-56. (ACS. Symposium series, 47).

ASSOCIATION OF OFFICIAL ANALYTICAL CHEMISTRY. Official methods of analysis of the Association of Official Analytical Chemists. 15. ed. Washingon, DC, 1990. 2 v.
BATISTA, L. R. Incidência de fungos produtores de ocratoxina A m grãos de café (Coffea arabica $L$ ) préprocessados por via seca e úmida. 2005.218 p. Tese (Doutorado em Ciência dos Alimentos) - Universisade Federal de Lavras, Lavras, 2005.

BORÉM, F. M. Pós-colheita do café. Lavras: UFLA/FAEPE, 2004. 103 p.

BRANDO, C. H. J. Cereja descascado, desmucilado, fermentado, despolpado ou lavado. In: CONGRESSO BRASILEIRO DE PESQUISAS CAFEEIRAS, 25., 1999, Franca. Anais... Rio de Janeiro: MAA/PROCAFÉ, 1999. p. 342-346.

CARVALHO, V. D. de; CHAGAS, S. J. de R.; CHALFOUN, S. M.; BOTREL, N.; JUSTE JUNIOR, E. S. G. Relação entre a composição fisico-química e química do grão beneficiado e qualidade de bebida do café. Pesquisa Agropecuária Brasileira, Brasília, v. 29, n. 3, p. 449-454, mar. 1994.

DRAETA, I. S.; LIMA, D. C. Isolamento e caracterização das polifenoloxidases do café. Coletânea do Instituto de Tecnologia de Alimentos, Campinas, v. 7, p. 3-28, 1976.

GIRANDA, R. N. Aspectos qualitativos de cafés (Coffea arábica, L.) submetidos a diferentes processos de secagem. 1998. 83 p. Dissertação (Mestrado em Ciência dos Alimentos) - Universidade Federal de Lavras, Lavras, 1998.

GUIMARÃES, A. C. Secagem de café (Coffea arabica L.) combinando sistemas em altas e baixas temperaturas. 1995 . 64 p. Dissertação (Mestrado em Engenharia Agrícola) Universidade Federal de Viçosa, Viçosa, 1995. 
INSTITUTO BRASILEIRO DO CAFÉ. Cultura do café no Brasil: manual do IBC. 2. ed. Rio de Janeiro, 1977. 235 p.

LEITE, A. R. Qualidade tecnológica do café (Coffea Arabica L.) Pré-Processado Por "Via Seca" e "Via Úmida". 1998. 64 p. Dissertação (Mestrado em Engenharia Agrícola) Universidade Federal de Lavras, Lavras, 1998.

LOEFFLER, T. M.; TEKRONY, D. M.; EGLI, D. B. The bulk conductivity test as na indicator of soybean quality. Journal of Seed Technology, Lansing, v. 12, n. 1, p. 37-53, 1988.

MALTA, M. R.; CHAGAS, S. J. de R.; OLIVEIRA, W. M. de. Composição físico-quimica e qualidade do café submetido a diferentes forma de pré-processamento. Revista Brasileira de Armazenamento, Viçosa, v. 25, n. 6, p. 30-36, 2003. Especial Café.

McDONALD, M. B. The history of seed vigor testing. Journal Seed Technology, Lansing, v. 17, n. 2, p. 93-100, 1993.

NELSON, N. A photometric adaptation of Somogy method for the determination of glucose. Journal of Biological Chemists, Baltmore, v. 153, n. 1, p. 375-384, 1944.

ORGANIZACIÓN INTERNACIONAL DEL CAFÉ. EI despulpado del café por medio de desmucilaginadoras mecánicas sin processo de fermentación y su efecto en la calidad de bebida de café producido em la región de Apucarana en el estado de Paraná em Brasil. Longres, 1992. Não paginado. (Reporte de Evaluación Sensorial).

ORNELLAS, L. H. Técnicas dietéticas: seleção e preparo de alimentos. 7. ed. rev. e ampl. São Paulo: Atheneu, 2001.

PEREIRA, R. G. F. A. Efeito da inclusão de grãos defeituosos na composição química qualidade do café (Coffea arábica L.) "estritamente mole". 1997. 96 p. Tese (Doutorado em Ciência dos Alimentos) - Universidade Federal de Lavras, Lavras, 1997.
PIMENTA, C. J.Época de colheita e tempo de permanência dos frutos à espera da secagem, na qualidade do café (Coffeea arabica L.). 2001. 145 p. Tese (Doutorado em Ciência dos Alimentos) - Universidade Federal de Lavras, Lavras, 2001.

PONTING, J. D.; JOSLYNG, M. A Ascorbic acd oxidation and browning in apple tissue extracts. Archives of Biochemistry, New York, v. 19, n. 1, p. 47-63, 1948.

PRETE, C. E. C. Condutividade elétrica do exsudato de grãos de café (Coffea arabica $\mathrm{L}$.) e sua relação com a qualidade da bebida. 1992. 125 p. Tese (Doutorado em Fitotecnia) Escola Superior de Agricultura Luiz de Queiroz, Piracicaba, 1992.

SILVA, R. F.; PEREIRA, R. G. F. A.; BORÉM, F. M.; MUNIZ, J. A. Qualidade do café-cereja descascado produzido na região sul de Minas Gerais. Ciência e Agrotecnologia, Lavras, v. 28, n. 6, p. 1367-1375, nov./dez. 2004.

SIQUEIRA, H. H. de. Análises físico-químicos e Sensoriais de Café de deferentes tipos de processamentos durante a torração. 2003. 57 p. Dissertação (Mestrado em Ciência dos Alimentos) - Universidade Federal de Lavras, Lavras, 2003.

STEGEN, V. G. H. D. Enhancement of coffee quality by moreld prevention. Food Controll, Oxford, v. 14, n. 4, p. 245-249, June 2003.

VILLELA, T. C. Qualidade do café despolpado, desmucilado, descascado e natural durante o processo de secagem. 2002. 69 p. Dissertação (Mestrado em Ciência dos Alimentos) Universidade Federal de Lavras, Lavras, 2002.

ZAPP, H. R.; EHLERT, S. H.; BROWN, G. K.; ARMSTRONG, P. R.; SOBER, S. Advanced instrumented sphere (IS) for impact measurements. Transactions of The ASAE, Saint Joseph, v. 33, n. 3, p. 955-960, May/June 1990. 